Pacific Journal of Mathematics

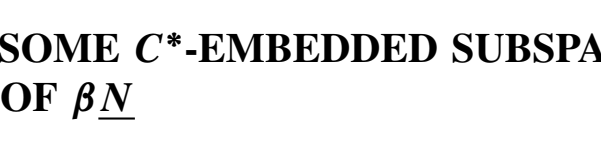




\title{
CHARACTERIZATIONS OF SOME $C^{*}$-EMBEDDED SUBSPACES OF $\beta \underline{N}$
}

\author{
R. GRant WoOdS
}

Let $K$ be a compact $F$-space such that $\left|C^{*}(K)\right|=2^{\omega}$. Using the continuum hypothesis we characterize those subspaces of $K$ that are $C^{*}$-embedded in $K$. We also characterize the class of extremally disconnected Tychonoff spaces of countable cellularity. As corollaries of these theorems, using various set-theoretic hypotheses we characterize the $C^{*}$ embedded, and the extremally disconnected $C^{*}$-embedded, subspaces of $\beta \underline{N}$.

1. Introdution. Our notation and terminology follows that of the Gillman-Jerison text [4]. All hypothesized topological spaces are assumed to be completely regular and Hausdorff (i.e., Tychonoff). As usual $\beta X$ denotes the Stone-Čech compactification of the Tychonoff space $X$, and $\underline{N}$ denotes the countable discrete space. $C^{*}(X)$ denotes the family of bounded real-valued continuous functions on $X$. A subspace $S$ of $X$ is $C^{*}$-embedded in $X$ if given $f \in C^{*}(S)$ there exists $g \in C^{*}(X)$ such that $g \mid S=f$. A cozero-set of $X$ is a set of the form $X-f^{\leftarrow}(0)$ where $f \in C^{*}(X)$. The collection of cozero-sets of $X$ is denoted by $\operatorname{coz}(X)$. A space $X$ is zero-dimensional if its open-andclosed (clopen) sets form a base for its open sets. $X$ is strongly zero-dimensional if $\beta X$ is zero-dimensional.

A space $X$ is weakly Lindelöf if given an open cover $\mathscr{Y}$ of $X$, there is a countable subfamily $\mathscr{C}$ of $\mathscr{V}$ such that $U \mathscr{C}$ is dense in $X$ (if $\mathscr{C}$ is a collection of subsets of a set we denote $U\{C: C \in \mathscr{C}$ \} by $\cup \mathscr{C}$ ). A space $X$ has the countable chain condition, or countable cellularity, if each family of pairwise disjoint nonempty open subsets of $X$ is countable. We abbreviate this by writing " $X$ has c.c.c." The following lemma, which came to the attention of the author through a letter from W.W. Comfort, is easily proved.

Lemma 1.1. A space has c.c.c. iff each of its open subsets is weakly Lindelöf.

A space $X$ is extremally disconnected if disjoint open subsets have disjoint closures. It is an $F$-space if its cozero-sets are $C^{*}$ embedded. It is an $F^{\prime \prime}$-space if disjoint cozero-sets have disjoint closures. Each extremally disconnected space is an $F$-space, and each $F$-space is an $F^{\prime}$-space. Proofs of these facts, plus other information on these classes of spaces, may be found in [1] and [4]. We shall 
need the following facts.

THEOREM $1.2(1 \mathrm{H}$ and $6 \mathrm{M}$ of [4]). The following are equivalent for a space $X$.

(1) $X$ is extremally disconnected.

(2) Each dense subspace of $X$ is extremally disconnected.

(3) Each open subspace of $X$ is extremally disconnected.

(4) Each dense subspace of $X$ is $C^{*}$-embedded in $X$.

(5) Each open subspace of $X$ is $C^{*}$-embedded in $X$.

TheOREM 1.3 (14.25 and 14.26 of [4]).

(1) Each $C^{*}$-embedded subspace of an $F$-space is an $F$-space.

(2) $X$ is an $F$-space iff $\beta X$ is an $F$-space.

The following lemma appears as the "note added on September 16,1968 " on page 494 of [1].

Lemma 1.4. If $X$ is an $F^{\prime}$-space and if each open subset of $X$ is weakly Lindelof, then $X$ is extremally disconnected.

Lemma 1.5 (Corollary 1.7 of [1]). Each weakly Lindelöf subspace of an $F^{\prime}$-space is $C^{*}$-embedded in its own closure.

The symbol $[\mathrm{CH}]$ preceding the statement of a theorem indicates that the continuum hypothesis $\left(2^{\omega}=\omega_{1}\right)$ is used in the proof of the theorem. The cardinality of a set $S$ is denoted by $|S|$. The weight of a topological space $X$, denoted by $w(X)$, is the least cardinal of a base for the open subsets of $X$. If $\alpha$ is a cardinal number then $D(\alpha)$ is the discrete space of cardinality $\alpha$ and $\log \alpha=\min \left\{\gamma: 2^{r} \geqq \alpha\right\}$.

Finally, we shall use the following theorem, which appears as Remark 8, page 274 of [2].

THEOREM 1.6. Each compact extremally disconnected space $K$ such that $w(K) \leqq 2^{\alpha}$ can be topologically embedded in $\beta D(\alpha)$.

2. $C^{*}$-embedded subsets of $\beta \underline{N}$. The proof of the implication in Theorem 2.2 that requires the continuum hypothesis-namely $(3) \rightarrow(1)$-relies heavily on a theorem, and a technique of proof, due to Fine and Gillman [3]. We first state the theorem.

THEOREM 2.1 (4.1(c) of [3]). Let $X$ be an $F$-space, let $\left\{S_{\alpha}: \alpha<\omega_{1}\right\}$ be a family of $\omega_{1}$ cozero-sets of $X$, and put $S=\bigcup_{\alpha<\omega_{1}} S_{\alpha}$. If $G \subset S$ and $G \cap S_{\alpha} \in \operatorname{coz}\left(S_{\alpha}\right)$ for each $\alpha<\omega_{1}$, then $G$ is $C^{*}$-embedded in $S$. 
We now state and prove the main theorem of this section.

THEOREM $2.2[\mathrm{CH}]$. Let $K$ be a compact $F$-space such that $\left|C^{*}(K)\right|=2^{\omega}$. Let $X$ be a subspace of $K$. The following are equivalent:

(1) $X$ is weakly Lindelöf.

(2) $X$ is $C^{*}$-embedded in $K$.

(3) $\left|C^{*}(X)\right|=2^{\omega}$.

\section{Proof.}

$(1) \rightarrow(2)$ : By $1.5 X$ is $C^{*}$-embedded in $\operatorname{cl}_{K} X$, which in turn is $C^{*}$-embedded in $K$ by the Urysohn extension theorem (see 3.11(c) of [4]).

(2) $\rightarrow(3)$ : Since $\left|C^{*}(K)\right|=2^{\omega}$ this is obvious.

$(3) \rightarrow(1)$ : Assume (1) fails; we shall prove that (3) fails also. Let $X$ be a subspace of $K$ that is not weakly Lindelöf. Let $\mathscr{V}$ be an open cover of $X$ which has no countable subcollection whose union is dense in $X$. By writing each member of of as the intersection of $X$ with a union of cozero sets of $\operatorname{cl}_{K} X$, and noting that $\operatorname{cl}_{K} X$ has only $2^{\omega}\left(=\omega_{1}\right)$ cozero subsets, we see that without loss of generality we may assume that $\mathscr{V}=\left\{A_{\alpha} \cap X: \alpha<\omega_{1}\right\}$, where each $A_{\alpha}$ is a cozero subset of $\operatorname{cl}_{K} X$. Put $U=\bigcup\left\{A_{\alpha}: \alpha<\omega_{1}\right\}$. Fix $\alpha_{0}<\omega_{1}$, and inductively assume that for each $\alpha<\alpha_{0}$, we have found a nonempty cozero-set $B_{\alpha}$ of $\mathrm{cl}_{K} X$ such that $B_{\alpha} \subset U$ and $\gamma<\alpha<\alpha_{0}$ implies that $B_{\alpha} \cap\left(A_{\gamma} \cup B_{\gamma}\right)=\varnothing$. Now $\bigcup_{\alpha<\alpha_{0}} A_{\alpha} \cup B_{\alpha}$ is a cozero-set of $\operatorname{cl}_{K} X$ contained in $U$. If it were dense in $U$, then as cozero-sets of compact spaces are Lindelöf there would be a countable subcollection $\mathscr{C}$ of $\left\{A_{\alpha}: \alpha<\omega_{1}\right\}$ whose union covers $\bigcup_{\alpha<\alpha_{0}} A_{\alpha} \cup B_{\alpha}{ }^{\cdot}$ Thus $\bigcup \mathscr{C}$ would be dense in $U$, and so $\{C \cap X: C \in \mathscr{C}\}$ would be a countable subfamily of $\mathscr{V}$ whose union is dense in $X$, contradicting hypothesis. Thus assume that $U-\mathrm{cl}_{K}\left(\mathrm{U}_{\alpha<\alpha_{0}} A_{\alpha} \cup B_{\alpha}\right) \neq \varnothing$. Hence a nonempty cozeroset $B_{\alpha_{0}}$ of $\operatorname{cl}_{K} X$ can be found such that $B_{\alpha_{0}} \cap\left(\mathrm{U}_{\alpha<\alpha_{0}} A_{\alpha} \cup B_{\alpha}\right)=\varnothing$ and $B_{\alpha_{0}} \subset U$. Now let $B=\bigcup_{\alpha<\omega_{1}} B_{\alpha}$. As $\gamma>\alpha$ implies $B_{r} \cap A_{\alpha}=\varnothing$, evidently $B \cap A_{\alpha}=\bigcup_{r \leqq \alpha} B_{\gamma} \cap A_{\alpha} \in \operatorname{coz}(U)$. Thus by $2.1 B$ is $C^{*-}$ embedded in $U$. But $B$ is the union of $\omega_{1}$ pairwise disjoint nonempty open subsets of $\operatorname{cl}_{K} X$, so $\left|C^{*}(B)\right| \geqq 2^{\omega_{1}}$. Thus $\left|C^{*}(U)\right| \geqq 2^{\omega_{1}}$ and as $X$ is dense in $U,\left|C^{*}(X)\right| \geqq 2^{\omega_{1}}>2^{\omega}$. Thus (3) fails, and the proof is complete.

REMARKS 2.3. (1) The hypotheses on $K$ in Theorem 2.2 are satisfied by a large class of spaces. One such class is the class of extremally disconnected spaces of weight no greater than $2^{\omega}$, such as $\beta \underline{N}$, or the absolute of a compact separable space (see [2] for details concerning absolutes of compact spaces). Another such class 
is the class of spaces of the form $\beta X-X$, where $X$ is a locally compact $\sigma$-compact non-compact space with $\left|C^{*}(X)\right|=2^{\omega}$ (see 14.27 of [4]); $\beta \boldsymbol{R}-\boldsymbol{R}$ is such a space, where $\boldsymbol{R}$ denotes the space of real numbers. Under assumption of the continuum hypothesis Theorem 2.2 gives a characterization of the $C^{*}$-embedded subspaces of each of these spaces.

(2) Let $K$ satisfy the hypotheses imposed in 2.2. One consequence of 2.2 is that the question of whether a subspace $X$ of $K$ is $C^{*}$-embedded in $K$ depends only on the topology of $X$ and not on "how $X$ is placed" in $K$. In the general case, by contrast, a space $T$ can contain two homeomorphic subspaces, one $C^{*}$-embedded in $T$ and the other not. For example the space $Q$ of rational numbers is $C^{*}$-embedded in $\beta Q$, but its homeomorphs $Q-\{0\}$ and $Q \cap(0, \infty)$, for example, are not $C^{*}$-embedded in $\beta Q$.

(3) If $2^{\omega_{1}}=2^{\omega}$ then Theorem 2.2 fails; for by $1.6 \beta D\left(\omega_{1}\right)$ could be topologically embedded in $\beta \underline{N}$. Hence $\beta N$ would contain a $C^{*}$ embedded copy of $D\left(\omega_{1}\right)$, which certainly is not weakly Lindelöf. I do not know whether Theorem 2.2 holds only if the continuum hypothesis holds; neither do I know whether the (possibly weaker) implication $(3) \rightarrow(2)$ can hold in the absence of the continuum hypothesis.

Theorem 2.2 tells us when a subspace of $\beta \underline{N}$ will be $C^{*}$-embedded in $\beta \underline{N}$. A slight generalization of a theorem of Louveau (stated below) allows us to characterize (assuming the continuum hypothesis) those Tychonoff spaces that are homeomorphic to some $C^{*}$-embedded subspace of $\beta \underline{N}$. The following theorem appears in [5].

Theorem $2.4[\mathrm{CH}]$. A compact space $K$ is homeomorphic to a subspace of $\beta \underline{N}$ iff $K$ is a zero-dimensional $F$-space and $w(K) \leqq 2^{\omega}$.

THEOREM $2.5[\mathrm{CH}]$. The following are equivalent for a space $X$ : (1) $X$ is a strongly zero-dimensional $F$-space and $\left|C^{*}(X)\right|=2^{\omega}$.

(2) $X$ is homeomorphic to a $C^{*}$-embedded subspace of $\beta \underline{N}$.

\section{Proof.}

$(1) \rightarrow(2): \quad$ By $1.3 \beta X$ is a compact zero-dimensional $F$-space and $\left|C^{*}(\beta X)\right|=2^{\omega}$. Thus $w(\beta X) \leqq 2^{\omega}$ so by 2.4 there is a compact subspace $K$ of $\beta \underline{N}$ and a homeomorphism $h: \beta X \rightarrow K$. Evidently $h[X]$ is homeomorphic to $X$ and $C^{*}$-embedded in $\beta \underline{N}$.

$(2) \rightarrow(1)$ : By hypothesis $\operatorname{cl}_{\beta} X=\beta X$. Thus $\beta X$ is zero-dimensional so $X$ is strongly zero-dimensional. As $\beta X$ is $C^{*}$-embedded in $\beta \underline{N}$, by $1.3 \beta X$ is an $F$-space and $\left|C^{*}(\beta X)\right|=2^{\omega}$. Hence $\left|C^{*}(X)\right|=$ $2^{\omega}$ and by $1.3 X$ is an $F$-space.

One interesting consequence of 2.2 and 2.5 is that if the con- 
tinuum hypothesis is assumed, if $X \subset \beta \underline{N}$ and $\left|C^{*}(X)\right|=2^{\omega}$ then $X$ is a strongly zero-dimensional $F$-space.

3. Extremally disconnected spaces of countable cellularity. By combining $1.1,1.5$, and 1.6 we obtain the following.

THEOREM 3.1. Let $X$ be a Tychonoff space of countable cellularity. The following are equivalent:

(1) $X$ is extremally disconnected.

(2) $X$ is homeomorphic to a subspace of $\beta D(\log w(\beta X))$. Further, if $X$ is homeomorphic to a subspace $Y$ of $\beta D(\alpha)$ for some $\alpha$, then $Y$ is $C^{*}$-embedded in $\beta D(\alpha)$.

Proof. Let $\beta D(\log w(\beta X))=K$.

$(1) \rightarrow(2): \quad \beta X$ is extremally disconnected (see $6 \mathrm{M}$ of [4]), so by $1.6 \beta X$ can be embedded in $K$.

$(2) \rightarrow(1)$ : We may assume $X \subset K$. As $K$ is extremally disconnected and hence an $F$-space, its $C^{*}$-embedded subspace $\operatorname{cl}_{K} X$ is an $F$-space. But $\operatorname{cl}_{K} X$ has c.c.c. as $X$ has; hence by 1.1 and $1.4 \operatorname{cl}_{K} X$ is extremally disconnected. Thus by $1.2 X$ is extremally disconnected. The final statement of the theorem follows from 1.1 and 1.5.

CoRollary 3.2. A separable Tychonoff space is extremally disconnected iff it is homeomorphic to a subspace of $\beta \underline{N}$.

Proof. If $X$ is separable then $w(\beta X) \leqq 2^{\omega}$ (as $\beta X$ will have no more than $2^{\omega}$ regular open subsets), so $\log (w(\beta X))=\omega$.

We now consider extremally disconnected $C^{*}$-embedded subspaces of $\beta \underline{N}$. Note that 3.1 says that a subspace $\beta \underline{N}$ having c.c.c. will be extremally disconnected and $C^{*}$-embedded in $\beta \underline{N}$. The following theorem describes when the converse holds.

THEOREM 3.3. The following are equivalent:

(1) $2^{\omega_{1}}>2^{\omega}$.

(2) Each extremally disconnected $C^{*}$-embedded subspace of $\beta \underline{N}$ has c.c.c.

Proof.

$(1) \rightarrow(2)$ : Suppose $X$ were an extremally disconnected $C^{*}$-embedded subspace of $\beta \underline{N}$ but that $X$ does not have c.c.c. Let $\mathscr{C}$ be a family of $\omega_{1}$ pairwise disjoint open subsets of $X$. By $1.2 \mathrm{U} \mathscr{C}$ is $C^{*}$ embedded in $X$ and hence in $\beta \underline{N}$. But evidently $\left|C^{*}(\mathrm{U} \mathscr{M})\right| \geqq 2^{\omega_{1}}$; thus $\left|C^{*}(\beta \underline{N})\right| \geqq 2^{\omega_{1}}$. But $\left|C^{*}(\underline{\beta} \underline{N})\right|=2^{\omega}$ so $2^{\omega}=2^{\omega_{1}}$. Hence if (2) 
fails, so does (1).

$(2) \rightarrow(1):$ If $2^{\omega_{1}}=2^{\omega}$ then $w\left(\beta D\left(\omega_{1}\right)\right)=2^{\omega}$. Thus by $1.6 \beta D\left(\omega_{1}\right)$ can be embedded in $\beta \underline{N}$. Hence there will be a $C^{*}$-embedded copy of $D\left(\omega_{1}\right)$ in $\beta \underline{N}$, and $D\left(\omega_{1}\right)$ is extremally disconnected but does not have c.c.c. Hence if (1) fails, so does (2).

REMarks 3.4. (1) Part of 3.3 appears as Corollary 10 of [2], where it is shown that $2^{\omega}<2^{\omega_{1}}$ iff each compact extremally disconnected space of weight $2^{\omega}$ has c.c.c.

(2) Not every compact subspace of $\beta \underline{N}$ with c.c.c. is separable. Let $B$ denote the Boolean algebra of Lebesgue measurable subsets of the unit interval, modulo sets of measure zero, and let $X$ denote the Stone space of $B$. Then $X$ is compact, extremally disconnected, has c.c.c., is not separable, and $w(X)=2^{\omega}$. Hence $X$ can be embedded in $\beta \underline{N}$. A discussion of $X$, together with references to further sources of information about it, may be found in Example 7.5 of [7].

(3) In Remark 2.3 (2) we have seen that if $2^{\omega_{1}}=2^{\omega}$ then $\beta \underline{N}$ has some discrete $C^{*}$-embedded subspaces of cardinality $\omega_{1}$. It would be interesting to know whether it is consistent that every discrete subspace of $\beta \underline{N}$ of cardinality $\omega_{1}$ is $C^{*}$-embedded in $\beta \underline{N}$. More generally, if one assumes, say, Martin's axiom [MA] but not $\mathrm{CH}$, is it true that each discrete subspace of $\beta \underline{N}$ of cardinality less than $2^{\omega}$ is $C^{*}$ embedded in $\beta \underline{N}$ ? (It is known that MA plus not $\mathrm{CH}$ implies that if $\kappa<2^{\omega}$ then $2^{\kappa}=2^{\omega}$; see, for example, page 21 of [6].)

(4) There is an interesting parallel between Theorems 2.2 and 3.3 as follows. Lemma 1.2 of [1] asserts that each cozero-set of a weakly Lindelöf space is weakly Lindelöf. Hence assuming the continuum hypothesis, a subspace of $\beta \underline{N}$ is $C^{*}$-embedded in $\beta \underline{N}$ iff all its cozero-sets are weakly Lindelöf; it is extremally disconnected and $C^{*}$-embedded in $\beta \underline{N}$ iff all its open subsets are weakly Lindelöf.

\section{REFERENCES}

1. W. W. Comfort, N. Hindman, and S. Negrepontis, $F^{\prime}$-spaces and their products with P-spaces, Pacific J. Math., 28 (1969), 489-502.

2. B. A. Efimov, Extremally disconnected compact spaces and absolutes, Trans. Moscow Math. Soc., 23 (1970), 243-285.

3. N. J. Fine and L. Gillman, Extensions of continuous functions in $\beta N$, Bull. Amer. Math. Soc., 66 (1960), 376-381.

4. L. Gillman and M. Jerison, Rings of continuous functions, Princeton: Van Nostrand (1960).

5. A. Louveau, Caracterisation des sous-espaces compacts de $\beta N$, Bull. Sci. Math. $2^{\ominus}$ série, 97 (1973), 259-263.

6. M. E. Rudin, Lectures on set-theoretic topology, C.B.M.S. Regional Conference series in mathematics No. 23 (1974).

7. F.D. Tall, The countable chain condition versus separability-applications of Martin's axiom, General Topology and its Applications, 4 (1974), 315-339. 
Received January 7, 1976 and in revised form April 12, 1976. The research discussed in this paper was conducted while the author was on sabbatical leave at the University of Wisconsin (Madison). The author would like to thank the Department of Mathematics at the University of Wisconsin, and particularly Mrs. Rudin, for their kind hospitality. The author also wishes to thank the referee for a number of useful suggestions. This research was partially supported by Grant No. A7592 from the National Research Council of Canada.

The UNIVERSity OF MANITOBA

WINNIPEG, CANADA 



\section{PACIFIC JOURNAL OF MATHEMATICS}

\section{EDITORS}

RICHARD ARENS (Managing Editor)

University of California

Los Angeles, California 90024

\section{R. A. Beaumont}

University of Washington

Seattle, Washington 98105
J. DugundjI

Department of Mathematics

University of Southern California

Los Angeles, California 90007

D. Gilbarg and J. Milgram

Stanford University

Stanford, California 94305

\section{ASSOCIATE EDITORS}
E. F. BECKENBACH
B. H. NeumanN
F. WOLF
K. YosHIDA

\section{SUPPORTING INSTITUTIONS}

\author{
UNIVERSITY OF BRITISH COLUMBIA \\ CALIFORNIA INSTITUTE OF TECHNOLOGY \\ UNIVERSITY OF CALIFORNIA \\ MONTANA STATE UNIVERSITY \\ UNIVERSITY OF NEVADA \\ NEW MEXICO STATE UNIVERSITY \\ OREGON STATE UNIVERSITY \\ UNIVERSITY OF OREGON \\ OSAKA UNIVERSITY
}

\author{
UNIVERSITY OF SOUTHERN CALIFORNIA \\ STANFORD UNIVERSITY \\ UNIVERSITY OF HAWAII \\ UNIVERSITY OF TOKYO \\ UNIVERSITY OF UTAH \\ WASHINGTON STATE UNIVERSITY \\ UNIVERSITY OF WASHINGTON \\ AMERICAN MATHEMATICAL SOCIETY
}

The Supporting Institutions listed above contribute to the cost of publication of this Journal, but they are not owners or publishers and have no responsibility for its content or policies.

Mathematical papers intended for publication in the Pacific Journal of Mathematics should be in typed form or offset-reproduced, (not dittoed), double spaced with large margins. Please do not use built up fractions in the text of your manuscript. You may however, use them in the displayed equations. Underline Greek letters in red, German in green, and script in blue. The first paragraph or two must be capable of being used separately as a synopsis of the entire paper. Items of the bibliography should not be cited there unless absolutely necessary, in which case they must be identified by author and Journal, rather than by item number. Manuscripts, in triplicate, may be sent to any one of the editors. Please classify according to the scheme of Math. Reviews, Index to Vol. 39. All other communications should be addressed to the managing editor, or Elaine Barth, University of California, Los Angeles, California, 90024.

The Pacific Journal of Mathematics expects the author's institution to pay page charges, and reserves the right to delay publication for nonpayment of charges in case of financial emergency.

100 reprints are provided free for each article, only if page charges have been substantially paid. Additional copies may be obtained at cost in multiples of 50 .

The Pacific Journal of Mathematics is issued monthly as of January 1966. Regular subscription rate: $\$ 72.00$ a year (6 Vols., 12 issues). Special rate: $\$ 36.00$ a year to individual members of supporting institutions.

Subscriptions, orders for back numbers, and changes of address should be sent to Pacific Journal of Mathematics, 103 Highland Boulevard, Berkeley, California, 94708.

PUBLISHED BY PACIFIC JOURNAL OF MATHEMATICS, A NON-PROFIT CORPORATION

Printed at Kokusai Bunken Insatsusha (International Academic Printing Co., Ltd.), 8-8, 3-chome, Takadanobaba, Shinjuku-ku, Tokyo 160, Japan. 


\section{Pacific Journal of Mathematics \\ Vol. 65, No. $2 \quad$ October, 1976}

Andrew Adler, Weak homomorphisms and invariants: an example .......... 293

Howard Anton and William J. Pervin, Separation axioms and metric-like

functions ............................................. 299

Ron C. Blei, Sidon partitions and p-Sidon sets .................... 307

T. J. Cheatham and J. R. Smith, Regular and semisimple modules ........... 315

Charles Edward Cleaver, Packing spheres in Orlicz spaces .............. 325

Le Baron O. Ferguson and Michael D. Rusk, Korovkin sets for an operator on a

space of continuous functions ............................. 337

Rudolf Fritsch, An approximation theorem for maps into Kan fibrations ....... 347

David Sexton Gilliam, Geometry and the Radon-Nikodym theorem in strict

Mackey convergence spaces .................................

William Hery, Maximal ideals in algebras of topological algebra valued

functions ...................................... 365

Alan Hopenwasser, The radical of a reflexive operator algebra ........... 375

Bruno Kramm, A characterization of Riemann algebras................. 393

Peter K. F. Kuhfittig, Fixed points of locally contractive and nonexpansive

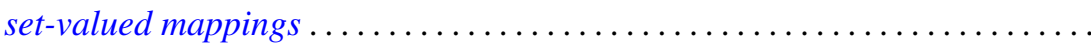

Stephen Allan McGrath, On almost everywhere convergence of Abel means of

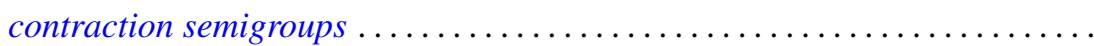

Edward Peter Merkes and Marion Wetzel, A geometric characterization of

indeterminate moment sequences............................ 409

John C. Morgan, II, The absolute Baire property ................... 421

Eli Aaron Passow and John A. Roulier, Negative theorems on generalized convex approximation .................................... 437

Louis Jackson Ratliff, Jr., A theorem on prime divisors of zero and characterizations of unmixed local domains ..............

Ellen Elizabeth Reed, A class of $T_{1}$-compactifications................... 471

Maxwell Alexander Rosenlicht, On Liouville's theory of elementary

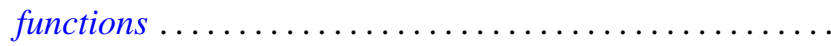

Arthur Argyle Sagle, Power-associative algebras and Riemannian

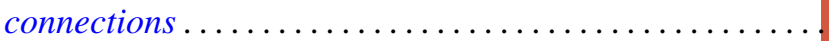

Chester Cornelius Seabury, On extending regular holomorphic maps from Stein manifolds...

Elias Sai Wan Shiu, Commutators and numerical ranges of powers of operators ...................................

Donald Mark Topkis, The structure of sublattices of the product of $n$ lattices ... 525

John Bason Wagoner, Delooping the continuous $K$-theory of a valuation

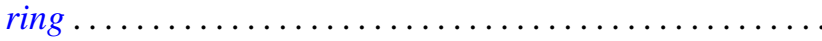

Ronson Joseph Warne, Standard regular semigroups...........

Anthony William Wickstead, The centraliser of $E \otimes_{\lambda} F \ldots$. 